\title{
Can chemical effects on cloud droplet number rival the first indirect effect?
}

\author{
Athanasios Nenes \\ Department of Chemical Engineering, California Institute of Technology, USA \\ Robert J. Charlson \\ Department of Atmospheric Sciences and Chemistry, University of Washington, USA \\ M. Cristina Facchini \\ Istituto di Scienze dell'Atmosfera e del Clima - CNR, Italy
}

Markku Kulmala

Department of Physical Sciences, University of Helsinki, Finland

Ari Laaksonen

Department of Applied Physics, University of Kuopio, Finland

John H. Seinfeld

Department of Chemical Engineering, California Institute of Technology, USA

Received 9 April 2002; revised 2 July 2002; accepted 9 July 2002; published 13 September 2002.

[1] An increase in cloud droplet number concentration resulting from an increase in ambient aerosol (and subsequent albedo increase) is typically identified as the first indirect (or "Twomey") climatic effect of aerosols [Twomey, 1974]. A key question is whether chemical effects (dissolution of soluble gases and slightly soluble substances, surface tension depression by organic substances and accommodation coefficient changes) could potentially rival changes in droplet number from changes in aerosol number concentration. We assess the sensitivity of cloud droplet number concentration to such chemical factors, using a cloud parcel model. We find that numerous conditions exist, for which chemical influences on cloud droplet activation can indeed rival the Twomey effect. INDEX TERMS: 0305 Atmospheric Composition and Structure: Aerosols and particles (0345, 4801); 0320 Atmospheric Composition and Structure: Cloud physics and chemistry; 0345 Atmospheric Composition and Structure: Pollution — urban and regional (0305). Citation: Nenes, A., R. J. Charlson, M. C. Facchini, M. Kulmala, A. Laaksonen, and J. H. Seinfeld, Can chemical effects on cloud droplet number rival the first indirect effect?, Geophys. Res. Lett., 29(17), 1848, doi:10.1029/2002GL015295, 2002.

\section{Introduction}

[2] Anthropogenic influences on cloud properties, better known as indirect climatic effect of aerosols, could constitute a major climate forcing [Intergovernmental Panel on Climate Change (IPCC), 2001]. A major challenge is to predict global cloud droplet number, $N_{d}$, from the precursor aerosol. While it is commonly assumed that the most important aerosol parameter influencing $N_{d}$ is aerosol number concentration, $N_{a}$, we present cases for which (unaccounted) chem-

Copyright 2002 by the American Geophysical Union. 0094-8276/02/2002GL015295 ical factors resulting from anthropogenic activities, can produce variations in $N_{d}$ comparable to those of the Twomey effect; if neglected, additional uncertainty can be introduced to current estimates of the aerosol indirect effect.

\section{Chemical Effects Considered in this Study}

[3] The chemical factors examined are the dissolution of soluble gases [Kulmala et al., 1993] and partially soluble solutes in the growing droplet [Shulman et al., 1996], surface tension $(\sigma)$ depression by dissolved organic substances [Shulman et al., 1996; Facchini et al., 1999] and accommodation coefficient changes from the formation of organic films at the droplet surface [Feingold and Chuang, 2002]. Of all the water soluble gas-phase species, probably the most important is nitric acid $\left(\mathrm{HNO}_{3}\right)$, since it is ubiquitous and can be found in relatively large concentrations (e.g., Fuzzi et al. [1992]).

[4] A water-soluble trace gas can provide enough solute to interstitial (or unactivated) cloud condensation nuclei $(\mathrm{CCN})$ so that they transform into activated droplets. Partially soluble species can also contribute solute, but, compared to soluble salts, are usually less efficient; this tends to increase the critical supersaturation, $S_{c}$, and also may lead to complex equilibrium curves [e.g., Shulman et al., 1996]. The highest $S_{c}$ is seen when the species becomes effectively insoluble. Dissolved substances can form films (in which the chemical composition differs from the bulk phase) so that the droplet $\sigma$, and thus $S_{c}$, decreases. We refer to these compounds as "surfactants" (although the usage of the term, in terms of the solubility, varies in the literature). Atmospheric compounds that exhibit significant surfactant behavior are usually water-soluble organic compounds (WSOC) [Shulman et al., 1996]. Changes in the osmotic coefficient (often assumed to be 1.0) from dissolved species can also affect $S_{c}$, but is not addressed in this 
study. Finally, a change in the water vapor accommodation (or condensation) coefficient, $\alpha$, will not necessarily affect droplet $S_{c}$, but can still strongly influence $N_{d}$ by modifying the timescale of droplet growth and the parcel maximum supersaturation, $S_{\max }$.

[5] As this study focuses on the aerosol-cloud droplet formation sensitivity, it is assumed that Köhler theory can be used to predict the CCN properties of the aerosol. Although this has been confirmed to within a reasonable degree for laboratory aerosol (e.g., Brechtel and Kreidenweis [2000a, 2000b]), measurements of ambient aerosol can exhibit significant discrepancy between predicted and measured CCN concentrations, with a tendency towards overprediction for polluted conditions [Chuang et al., 2000; Brechtel and Kreidenweis, 2000b]. It is still unclear, however, how much of this discrepancy is a result of incomplete theory or instrumental biases.

\section{Description of Simulations}

[6] To examine the potential importance of chemical effects on $N_{d}$, we simulate $N_{d}$ (using an adiabatic cloud parcel model with explicit aerosol microphysics, [Nenes et al., 2001]) relative to a baseline case. The "Twomey effect" is assessed by calculating the change in $N_{d}$ for a doubling of the baseline $N_{a}$. We then compare the Twomey effect to the change in $N_{d}$ seen with no changes in size distribution (only chemistry).

[7] $N_{d}$ depends on updraft velocity (or cooling rate), $U$, soluble gas concentration, and aerosol size distribution and chemical characteristics. $U$ varies between 0.1 and $3 \mathrm{~m} \mathrm{~s}^{-1}$. To assess cloud droplet concentration, we employ the criterion used in Nenes et al. [2001], which is to find the $\mathrm{CCN}$ of highest $S_{c}$ that strictly activates (i.e., exceeds its critical diameter); anything larger than this $\mathrm{CCN}$ is counted as a drop. Note that this definition accounts for mass transfer limitations: large $\mathrm{CCN}$ that have not attained their critical diameter are considered as droplets, but not those that deactivate and become interstitial aerosol. Droplet concentration is evaluated at $250 \mathrm{~m}$ above cloud base. The parcel pressure, temperature, and relative humidity are initially set at $800 \mathrm{mbar}, 273 \mathrm{~K}$, and $98 \%$, respectively.

[8] The aerosol is assumed to be an internal mixture of $\left(\mathrm{NH}_{4}\right)_{2} \mathrm{SO}_{4}$, organic, and an insoluble substance. The osmotic coefficient is assumed to be 1.0. The aerosol organic component is a simplification of chemical composition observed in Po Valley fogs and is assumed to be composed of $18 \%$ (by mass) levoglucosan $\left(\mathrm{C}_{6} \mathrm{H}_{10} \mathrm{O}_{5}\right.$, density $=1600$ $\mathrm{kg} \mathrm{m}^{-3}$, van't Hoff factor $=1$ ), $41 \%$ (by mass) succinic acid $\left(\mathrm{C}_{6} \mathrm{O}_{4} \mathrm{H}_{6}\right.$, density $=1572 \mathrm{~kg} \mathrm{~m}^{-3}$, van't Hoff factor $\left.=3\right)$, and $41 \%$ (by mass) fulvic acid [US Geological Survey, 1979], $\left(\mathrm{C}_{33} \mathrm{H}_{32} \mathrm{O}_{19}\right.$, density $=1500 \mathrm{~kg} \mathrm{~m}^{-3}$, van't Hoff factor $\left.=5\right)$. As samples from completely different environments tend to exhibit similar behavior [Charlson et al., 2001] we used the curve reported in Facchini et al. [1999] to describe the $\sigma$ depression for all types of aerosol that contain WSOC. The organic mixture is assumed to be either completely soluble, or with solubility, $\Gamma$, varying between $10^{-4}$ and $10^{-1} \mathrm{M}$. When present, the film forming compound (FFC) follows the behavior proposed by Feingold and Chuang [2002], in which $\alpha$ has a low value when a film exists, and then attains a large value once the film breaks. The FFC is part of the insoluble fraction, and has a density of $1760 \mathrm{~kg} \mathrm{~m}^{-3}$. Furthermore, $\alpha=10^{-5}$ when the film exists, and 0.043 , after the film breaks. The film exists when its thickness is larger than $0.5 \mathrm{~nm}$. The insoluble fraction has a density of $1760 \mathrm{~kg} \mathrm{~m}^{-3}$. Feingold and Chuang [2002] found that when the FFC is distributed according to the surface area of single mode lognormal aerosol, $N_{d}$ is suppressed. This is still expected to hold for ambient aerosol, as the growth of CCN with high $S_{c}$ are mostly affected in this configuration. Feingold and Chuang [2002] also presented simulations assuming that the FFC mass fraction is constant throughout the size distribution, and found that $N_{d}$ is effectively unchanged. Given that their simulations do not contain many large $\mathrm{CCN}$, we perform simulations with a constant mass fraction of FFC, for multimodal aerosol, to examine whether the inhibition of the growth of larger $\mathrm{CCN}$ would lead to an increase of droplet number.

[9] At this point, we would like to clarify that the definition of film as used in Feingold and Chuang [2002] differs from the film that forms in any surfactant system; the former reflects the water vapor permeability, while the latter reflects a region adjacent to the surface with composition different from the bulk. Furthermore, in this work and the Feingold and Chuang [2002] study, it is assumed that the film is unconditionally stable, so that all of the FFC mass remains in the film. This configuration reflects the maximum possible influence of FFCs on droplet growth. Insoluble surfactants, which are candidate FFC, tend to form micelles in the aqueous phase (or precipitate) when present in quantities larger than that to form a few monolayers [Miller and Neogi, 1985]. In this case, the film, depleted from FFC, would break and the $\mathrm{CCN}$ would resume rapid growth sooner. The actual fate of the FFC, and how that would influence the droplet thermodynamics and water vapor condensation kinetics are issues that need to be addressed in future studies.

[10] The baseline case selected depends on the chemical effect examined. For $\alpha$ effects, the baseline is assumed to be $10 \%$ by mass insoluble for marine and $50 \%$ for urban aerosol; the remainder of the aerosol is assumed to be $\left(\mathrm{NH}_{4}\right)_{2} \mathrm{SO}_{4}$. For all other chemical effects, the baseline aerosol is assumed to be pure $\left(\mathrm{NH}_{4}\right)_{2} \mathrm{SO}_{4}$.

[11] We consider the marine and urban tri-modal lognormal aerosol size distributions of Whitby [1978] to represent pristine and polluted aerosol, respectively. The marine distribution mode diameters are $0.01,0.071,0.62$ $\mu \mathrm{m}$, their corresponding dispersions are 1.6, 2.0, 2.7 and the number concentrations are $340,60,3.1 \mathrm{~cm}^{-3}$. The urban distribution mode diameters are $0.014,0.054,0.86 \mu \mathrm{m}$, their corresponding dispersions are 1.8, 2.16, 2.21 and the number concentrations are $106000,32000,5.4 \mathrm{~cm}^{-3}$.

\section{Sensitivity of Cloud Properties to Chemical Effects}

[12] Figures 1 and 2 shows $N_{d}$ normalized to the baseline $N_{d}$, as a function of $U$, for the pristine and polluted aerosol, respectively. The "Twomey" simulation is same as the pure $\left(\mathrm{NH}_{4}\right)_{2} \mathrm{SO}_{4}$ baseline, but with aerosol concentrations doubled. " $\mathrm{HNO}_{3}$ " is same as the baseline simulation, with $5 \mathrm{ppb} \mathrm{HNO}_{3}$ initially in the gas phase, which is within measured values in plumes advected off the northeast United States (G. Huey, personal communication). The "Surface 


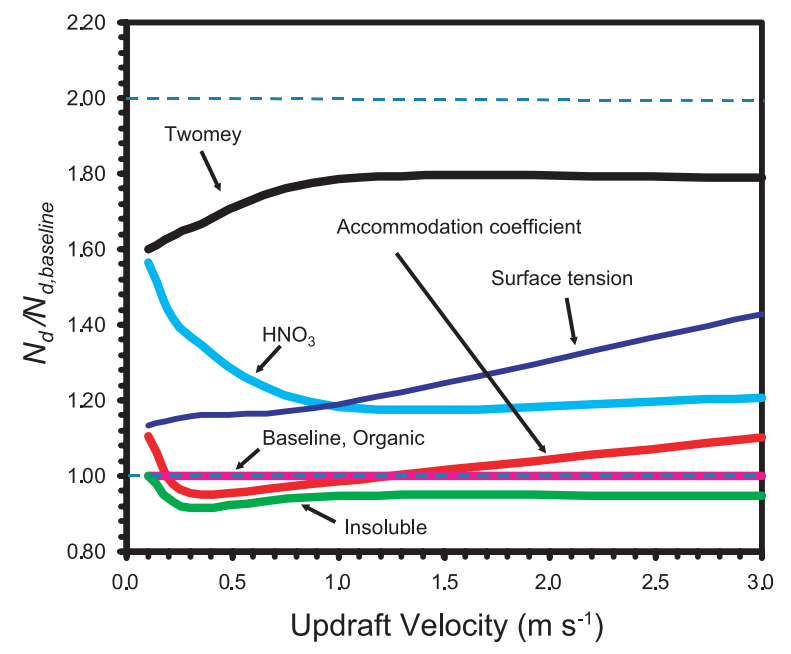

Figure 1. Droplet number concentration normalized to the baseline $N_{d}$, as a function of updraft velocity, for marine aerosol size distributions.

tension" corresponds to an aerosol composed of (by mass) $75 \%\left(\mathrm{NH}_{4}\right)_{2} \mathrm{SO}_{4}$, and $25 \%$ organic. The organic is completely soluble, acts as a surfactant, and $\alpha=1.0$. "Organic" is same as "Surface tension" simulation, without $\sigma$ effects included. "Insoluble" corresponds to an aerosol composed $75 \%$ (by mass) $\left(\mathrm{NH}_{4}\right)_{2} \mathrm{SO}_{4}$, and $25 \%$ insoluble, and $\alpha=1.0$. Finally, "Accommodation coefficient" assumes the aerosol contains $10 \%$ by mass FFC; an additional $40 \%$ by mass insoluble is assumed to exist in the polluted aerosol. The remaining mass is $\left(\mathrm{NH}_{4}\right)_{2} \mathrm{SO}_{4}$.

[13] Between $7 \%\left(U=0.1 \mathrm{~m} \mathrm{~s}^{-1}\right)$ and $18 \%\left(U=3 \mathrm{~m} \mathrm{~s}^{-1}\right)$ of the aerosol activates in the pure $\left(\mathrm{NH}_{4}\right)_{2} \mathrm{SO}_{4}$ baseline case. The presence of insoluble material in the aerosol tends to increase the $S_{c}$ of the particles, which results in a reduction of the water vapor condensation in the initial stages of cloud formation. As a result, the parcel tends to attain a higher $S_{\max }$ to compensate for any loss in droplets by activating CCN of higher $S_{c}$. The simulations for marine conditions show no change in $N_{d}$ for weak updrafts, and a small decrease at stronger updrafts. Under urban conditions, the insoluble substance does not substantially change $N_{d}$ regard-

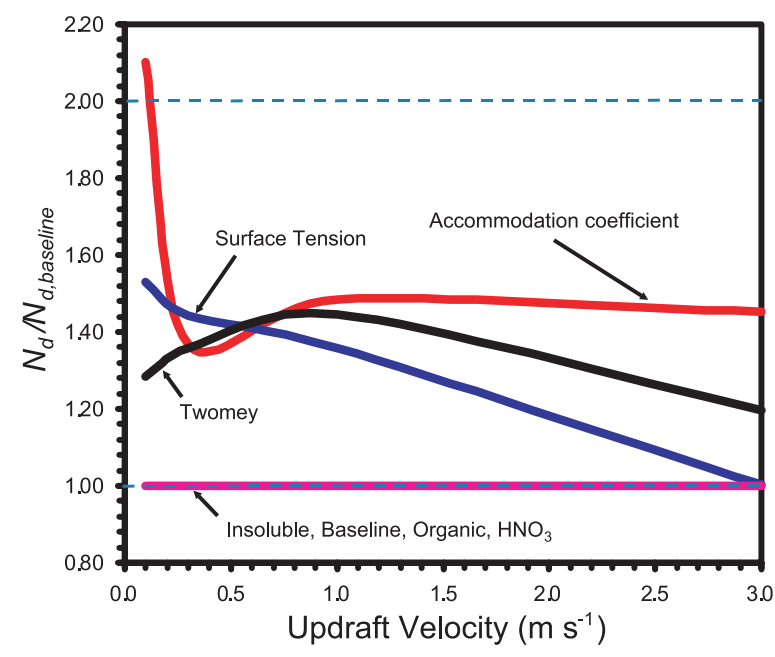

Figure 2. Same as Figure 1, but for the urban size distribution.

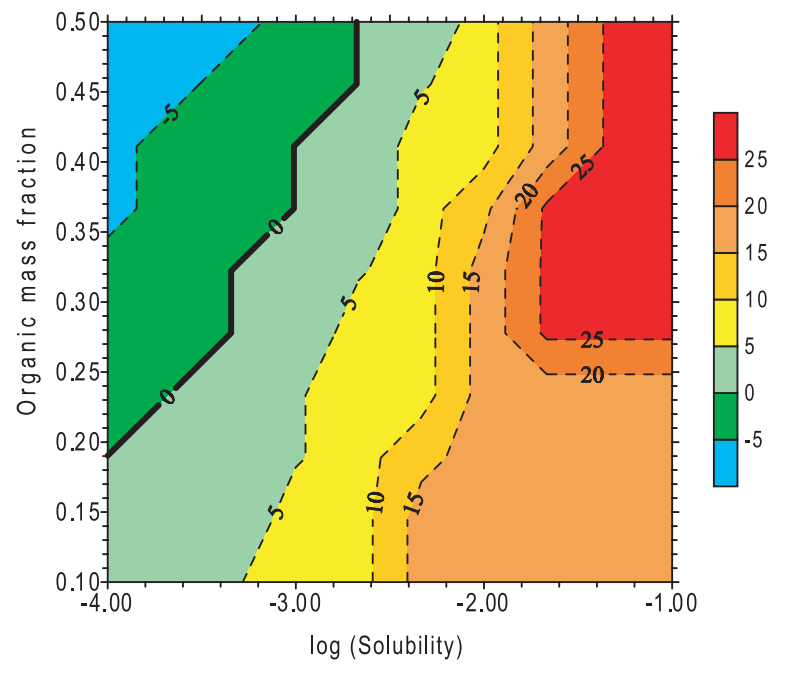

Figure 3. Isopleth contours of cloud droplet number concentration change (\%) relative to the baseline simulation, with respect to the logarithm of solubility (moles $\mathrm{L}^{-1}$ ) and organic mass fraction of aerosol. The $\sigma$ effects are as described in the text. Marine conditions and an updraft velocity equal to $1 \mathrm{~m} \mathrm{~s}^{1}$ are assumed in these calculations.

less of $U$ (for higher values of insoluble fraction, the change in cloud droplet concentration does becomes significant).

[14] The presence of $\mathrm{HNO}_{3}$ dissolving in the droplets can substantially increase $N_{d}$. The effect is most pronounced for weak updrafts because $\mathrm{HNO}_{3}$ is partitioned amongst fewer droplets, and more time is allowed for the soluble gas to dissolve in the droplets. This results in a larger amount of $\mathrm{HNO}_{3}$ dissolved per droplet, and large reductions in $S_{c}$. That the soluble gas effect is strongest for weak as opposed to strong updrafts is an important distinction from other chemical effects. Under urban conditions, the effect of $\mathrm{HNO}_{3}$ on $N_{d}$ is negligible because the amount of solute partitioned in each particle, and its subsequent effect on $S_{c}$, is small. One cannot conclude, however, that polluted clouds are never affected by soluble gas dissolution; important $\mathrm{HNO}_{3}$ effects can be seen for moderately polluted aerosol [Kulmala et al., 1996].

[15] The presence of a WSOC, even if it does not act as a surfactant, alters the activation behavior of the aerosol by changing the moles of dissolved solute in each droplet. The organic mixture activation behavior is not substantially different from $\left(\mathrm{NH}_{4}\right)_{2} \mathrm{SO}_{4}$ and therefore the "Organic" simulation behaves identically to the baseline (for both marine and urban conditions). Once $\sigma$ changes are introduced, $N_{d}$ increases regardless of $U . \sigma$ effects can be important for both marine and urban aerosol. For the marine distribution, the strongest effects are seen at high $U$, and for the urban, at low $U$. For the marine aerosol, the $\sigma$ effect can become as much as $50 \%$ of the Twomey effect, while for the urban, $\sigma$ effects can exceed the Twomey effect.

[16] In Figures 1 and 2, we have assumed that the WSOC is completely soluble. Although the parameterization of WSOC concentration and $\sigma$ corresponds to a highly complex mixture, it is possible that substances, not represented in the measurements, can decrease the WSOC solubility; this can potentially affect its ability to change droplet number and needs to be examined. This is done in Figure 3, which shows the fractional change in $N_{d}$ with respect to the organic mass 
fraction, $\varepsilon_{o}$, and $\Gamma$. In these simulations, $\alpha$ is assumed to be unity, and the dissolved organic is assumed to decrease droplet $\sigma$.

[17] At the $\Delta N / N=0$ contour, the effects from decreased inorganic solute and $\sigma$ exactly compensate for each other, and the aerosol behaves (on average) as if it were composed entirely of $\left(\mathrm{NH}_{4}\right)_{2} \mathrm{SO}_{4}$. To the left of the $\Delta N / N=0$ contour (Figure 3), dissolved organics do not compensate for the decrease in inorganic solute. Comparing the "Insoluble" simulation of Figure 1 with Figure 3, we can see that for $\Gamma<$ $10^{-4} \mathrm{M}$, the organic behaves as if it were insoluble. To the right of the line, overcompensation occurs. Depending on $\varepsilon_{o}$, larger values of $\Gamma$ can notably increase $N_{d}$. The largest decrease in $\sigma$ occurs when the volume of water in the droplet is precisely that needed to completely dissolve the organic; further solubility will not affect droplet formation. Indeed, by comparing "Surface tension" simulation from Figures 1 and 3 , we see that $\Gamma>5 \times 10^{-2} \mathrm{M}$ displays the same effect on $N_{d}$. Thus, a significant decrease in the $\Gamma$ will not significantly hinder the ability of WSOC to enhance droplet formation.

[18] When $\alpha$ decreases, the rate of water absorption in the cloud decreases in the initial stages of its formation (since droplets do not grow as rapidly); this leads to a higher $S_{\max }$. If $\alpha$ remained constant for all CCN (meaning that the film never breaks), the resulting effect would always be an increase in $N_{d}$, since all $\mathrm{CCN}$ are equally delayed in their activation (simulations indicate that for urban distributions, $N_{d}$ can increase threefold from $\alpha=1.0$ to 0.01 , and tenfold from $\alpha=0.01$ to 0.001 , for $U=1.0 \mathrm{~m} \mathrm{~s}^{-1}$ ). However, when a threshold transition between a low and a high $\alpha$ is assumed, $N_{d}$ can either increase or decrease, depending on how the film-forming substance is distributed throughout the size distribution. For the simulations carried out in this study, we can see that $\alpha$ effects are rather small for the marine aerosol. This conclusion is consistent with the simulations of Feingold and Chuang [2002], as the larger $\mathrm{CCN}$ are too few to have a significant impact on $N_{d}$. For the urban aerosol, on the other hand, the aerosol number is enhanced substantially, as the inhibition of the larger CCN growth significantly increases $S_{\max }$ and allows water vapor to condense on smaller particles.

\section{Conclusions}

[19] Numerous conditions are found for which chemical effects on droplet activation can be significant when compared to the Twomey effect; in some cases, chemical effects can be even larger. All effects exhibit strong dependence on the magnitude of $U$. For WSOC, the lowering of $\sigma$ is predicted to have a stronger effect on activation than its contribution to the Raoult effect; thus, even though both effects need to be considered, uncertainties in the $\sigma$ behavior of the aerosol may be more influential than uncertainties in the solute contribution alone.

[20] The dissolution of a soluble gas during droplet formation can also have a large impact on $N_{d}$. In contrast to other chemical effects, higher $U$ (and, as a consequence, higher $N_{d}$ ) diminish the impact of a soluble gas, as increased $N_{d}$ and shorter dissolution times lead to less solute introduced per droplet.

[21] If both surfactants and condensable gases are present, they can act synergistically to increase $N_{d}$, i.e., for dynamical conditions where one effect is negligible, the other can become influential. This is an important point: given that large variability in updrafts occurs in real clouds, it is quite possible that marine clouds affected by polltion can experience an even larger enhancement in $N_{d}$ than previously thought. The influence of WSOC can be even larger if they are distributed according to the CCN surface area, since a larger mass of WSOC will be found on CCN with high $S_{c}$. Finally, if the aerosol contains a FFC, the resulting effect can have a substantial effect on $N_{d}$, either positive or negative.

[22] Acknowledgments. A. Nenes and J. H. Seinfeld were supported by U.S. Office of Naval Research grant N00014-96-1-0119. We would also like to thank P. Y.Chuang and J.Snider for their important comments during the review process. Finally, we would like to acknowledge M. Mircea for helpful suggestions during the preparation of the manuscript.

\section{References}

Brechtel, F. J., and S. M. Kreidenweis, Predicting particle critical supersaturation from hygroscopic growth measurements in the humidified TDMA, Part I: Theory and sensitivity studies, J. Aerosol Sci., 57, 1854-1871, 2000a.

Brechtel, F. J., and S. M. Kreidenweis, Predicting particle critical supersaturation from hygroscopic growth measurements in the humidified TDMA, Part II: Laboratory and ambient studies, J. Aerosol Sci., 57, $1872-1887,2000$ b.

Charlson, R., J. Seinfeld, A. Nenes, M. Kulmala, A. Laaksonen, and M. Facchini, Atmospheric science - reshaping the theory of cloud formation, Science, 292, 2025-2026, 2001.

Chuang, P., D. Collins, H. Pawlowska, J. Snider, H. Jonsson, J. L. Brenguier, R. Flagan, and J. Seinfeld, CCN measurements during ACE-2 and their relationship to cloud microphysical properties, Tellus B, 52, 843$867,2000$.

Facchini, M., M. Mircea, S. Fuzzi, and R. Charlson, Cloud albedo enhancement by surface-active organic solutes in growing droplets, Nature, 401, 257-259, 1999

Feingold, G., and P. Chuang, Analysis of the influence of film-forming compounds on droplet growth: Implications for cloud microphysical processes and climate, J. Atmos. Sci., 59, 2006-2018, 2002.

Fuzzi, S., et al., The Po Valley fog experiment 1989, an overview, Tellus B, 44, 448-468, 1992.

Intergovernmental Panel on Climate Change (IPCC), Climate Change (2001): The Scientific Basis, Cambridge University Press, UK, 2001.

Kulmala, M., A. Laaksonen, P. Korhonen, T. Vesala, T. Ahonen, and J. Barrett, The effect of atmospheric nitric acid vapor on cloud condensation nucleus activation, J. Geophys. Res., 98, 22,949-22,958, 1993.

Kulmala, M., P. Korhonen, T. Vesala, H. Hansson, K. Noone, and B. Svenningsson, The effect of hygroscopicity on cloud droplet formation, Tellus B, 48, 347-360, 1996

Miller, C., and P. Neogi, Interfacial Phenomena: Equilibrium and Dynamic Effects, Marcel Dekker, New York, 1985.

Nenes, A., S. Ghan, H. Abdul-Razzak, P. Chuang, and J. Seinfeld, Kinetic limitations on cloud droplet formation and impact on cloud albedo, Tellus $B, 53,133-149,2001$.

Shulman, M., M. Jacobson, R. Charlson, R. Synovec, and T. Young, Dissolution behaviour and surface tension effects of organic compounds in nucleating cloud droplets, Geophys. Res. Lett., 23, 277-280, 1996.

Twomey, S., Pollution and the planetary albedo, Atmos. Environ., 8, $1251-$ $1256,1974$.

US Geological Survey, Suwanee river certified FA standards, Report 87557,1979 .

Whitby, K., The physical characteristics of sulfur aerosols, Atmos. Environ., 12, 135-159, 1978 .

A. Nenes and J. H. Seinfeld, Department of Chemical Engineering, California Institute of Technology, Pasadena, CA 91125, USA. (nenes@) caltech.edu; seinfeld@caltech.edu)

R. J. Charlson, Departments of Atmospheric Sciences and Chemistry, University of Washington, Box 351700, Seattle, WA 98195, USA. (charlson@chem.washington.edu)

M. C. Facchini, Istituto di Scienze dell'Atmosfera e del Clima - C.N.R., Via Gobetti 101, 40129 Bologna, Italy. (mc.facchini@isac.cnr.it)

M. Kulmala, Department of Physical Sciences, University of Helsinki, PO Box 64, FIN - 00014, Finland. (markku.kulmala@helsinki.fi)

A. Laaksonen, Department of Applied Physics, University of Kuopio, PO Box 1627, 70211 Kuopio, Finland. (ari.laaksonen@uku.fi) 